EECCIÓN: Teorías geográficas, geografía de la

cultura y la vida cotidiana
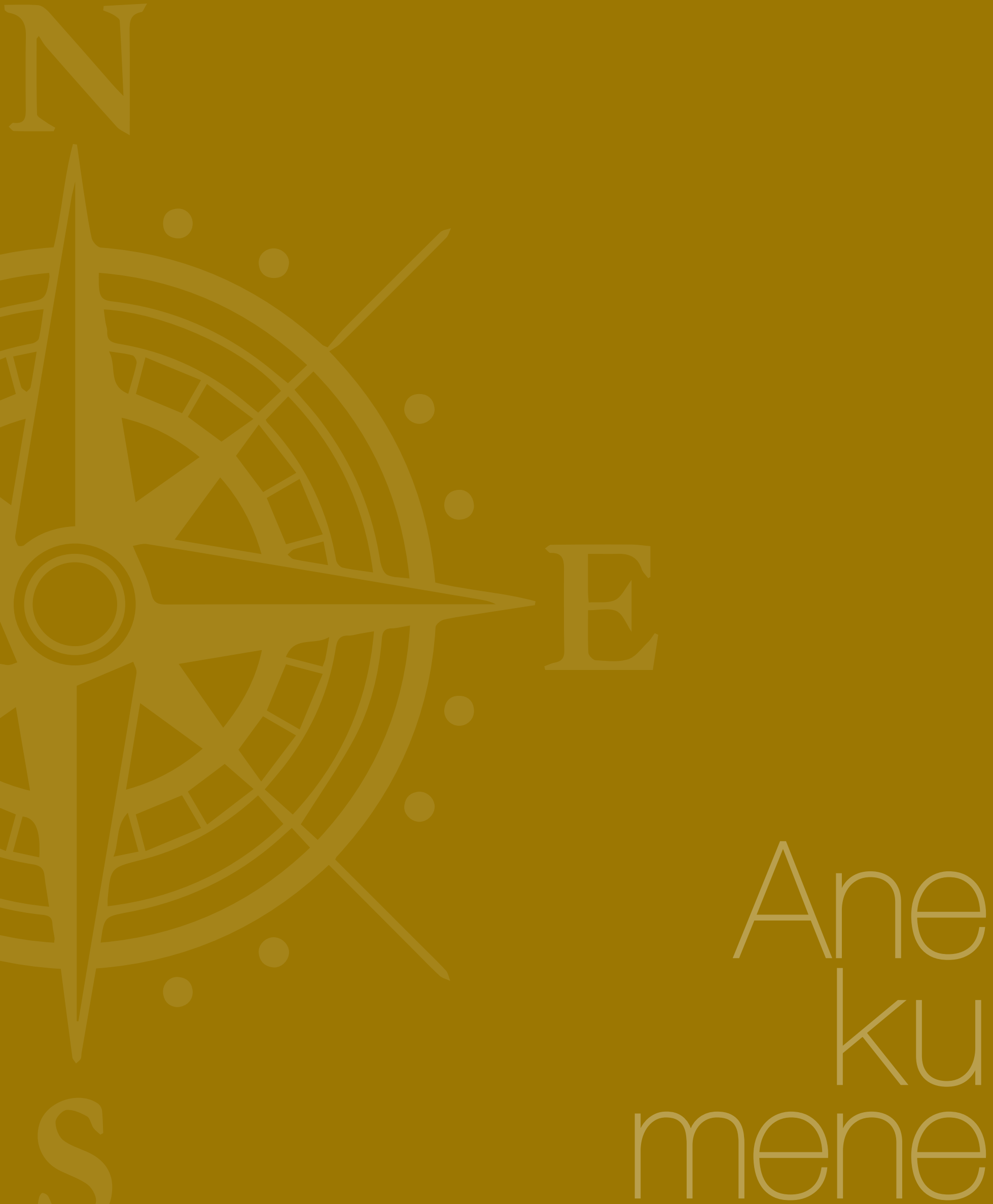


\section{As relações entre o desenvolvimento do pensamento espacial (spatial thinking) e a cartografia escolar nas aulas de geografia: uma análise dos manuais didáticos brasileiros}

\section{Relationships between the Development of Spatial Thinking and School Cartography in Geography Class: An Analysis of Brazilian Teaching Manuals}

\section{Las relaciones entre el desarrollo del pensamiento espacial (spatial thinking) y la cartografía escolar en las clases de geografía: un análisis de los manuales didácticos brasileros}

Ronaldo Goulart Duarte*

\begin{abstract}
Resumo
Neste artigo apresentamos uma breve análise a algumas conclusões resultantes do exame cuidadoso das atividades didáticas presentes nas três coleções de livros didáticos de geografia mais utilizadas pelos alunos brasileiros que estudam na etapa da escolarização entre o $6^{\circ} \mathrm{e}$ o $9^{\circ}$ anos do ensino fundamental. Nossa análise está fundamentada no campo teórico do pensamento espacial (spatial thinking), campo de estudos interdisciplinares que transita entre as áreas de interesse de diversas disciplinas, com certo destaque para a psicologia cognitiva, a matemática e a geografia, entre muitos outros. Usamos como referência
\end{abstract}

metodológica a taxonomia do pensamento espacial desenvolvida por Jo e Bednarz (2009) e replicada por Scholz, Huynh, Brysch, e Scholz (2014). Essencialmente, trata-se de avaliar os exercícios e atividades presentes nos livros didáticos com o objetivo de aferir o percentual daqueles que, efetivamente, demandam o uso do pensamento espacial e averiguar quais os processos de raciocínio que estão envolvidos.

\section{Palavras-chave}

Pensamento espacial; cartografia escolar; manuais didáticos

\footnotetext{
* Prof. Assistente UERJ
} 


\begin{abstract}
In this paper, we present some conclusions and a brief analysis obtained through careful examination of the questions in the three most adopted Brazilian geography textbook sets, designed for the equivalent to junior high school in Brazil. Our analysis is based on the field known as "spatial thinking," an interdisciplinary field that lies between different academic disciplines such as cognitive psychology, math, geography, and many others. We used, as a methodological framework, the taxonomy of spatial thinking developed by Jo and Bednarz (2009) and applied by Scholz, Huynh, Brysch, and Scholz (2014). Essentially, the main goal was to evaluate the questions in the textbooks with the purpose of measuring the proportion of those that demand the use of spatial thinking to be solved and to identify the processes of reasoning involved.
\end{abstract}

\section{Resumen}

En este artículo, presentamos un breve análisis de algunas conclusiones resultantes de un examen cuidadoso de las actividades didácticas presentes en las tres colecciones de libros didácticos de geografía más utilizados por los estudiantes brasileños que estudian en el período de escolaridad entre el $6^{\circ}$ y el $9^{\circ}$ año de la enseñanza fundamental. Nuestro análisis se basa en el campo teórico del pensamiento espacial (spatial thinking), un campo interdisciplinario que atraviesa las áreas de interés de varias disciplinas, con un cierto énfasis en la psicología cognitiva, la matemática y la geografía, entre otros. Usamos como referencia metodológica la taxonomía del pensamiento espacial desarrollada por Jo y Bednarz (2009) y replicada por Scholz, Huynh, Brysch y Scholz (2014). Esencialmente, se trata de evaluar los ejercicios y actividades presentes en los libros didácticos con el objetivo de evaluar el porcentaje de aquellos que, efectivamente, exigen el uso del pensamiento espacial y descubren qué procesos de raciocinio están involucrados.

\section{Keywords}

Spatial thinking; school cartography; textbooks

\section{Palabras clave}

Pensamiento espacial; cartografía escolar; manuales didácticos 


\section{Introdução}

No ensino de Geografia brasileiro, e também em outros países latino-americanos, é comum nos depararmos com a crítica de que existe um subaproveitamento, ou mesmo uma negligência no que se refere à Cartografia Escolar. As queixas são diversificadas e vão desde o abandono puro e simples do mapa como recurso didático, até o seu uso limitado à condição de ilustração ou de referência para a localização dos fenômenos e das formas espaciais.

O entendimento da centralidade da linguagem cartográfica para a formação cidadã em geral e para o ensino da Geografia em particular, levaram-nos a nos unir àqueles que labutam pela construção coletiva de novos e consistentes caminhos para a utilização pedagógica do mapa como instrumental fundamental para que se atinjam os objetivos do ensino de Geografia na escola básica. Com o objetivo de construir de forma mais consistente esse elo, elegemos o campo teórico do Pensamento Espacial (Spatial Thinking) como fundamento primordial de nossa investigação. O pensamento espacial constitui um campo de estudos interdisciplinares que transita entre as áreas de interesse de diversas disciplinas, com certo destaque para a Psicologia Cognitiva, a Matemática e a Geografia, mas envolvendo também, ainda que não com os mesmos objetivos, a Arquitetura, a Medicina, as Engenharias, entre muitas outras. Nos países anglo-saxônicos essa área de pesquisas cresceu bastante nos últimos 15 anos e a adesão de pesquisadores da área da Educação Geográfica a esses estudos seguiu a mesma tendência.

Baseados nessa estrutura teórica, nos dispusemos a analisar os exercícios e atividades presentes nas três coleções de livros didáticos de Geografia mais utilizadas pelos alunos brasileiros que estudam no segmento intermediário da escolarização, referente à etapa entre o $6^{\circ} \mathrm{e} \circ 9^{\circ}$ anos do ensino fundamental ${ }^{1}$. Para isso, usamos como referência e taxonomia do pensamento espacial desenvolvida por Jo e Bednarz (2009) e replicada por Scholz, Huynh, Brysch, e Scholz (2014). Essencialmente, trata-se de avaliar os exercícios e atividades presentes nas coleções de livros didáticos com o objetivo de aferir o percentual desses exercícios e atividades que efetivamente demandam o uso do pensamento espacial e averiguar quais os processos de raciocínio que estão envolvidos.

\section{Pensamento Espacial (Spatial Thinking)}

O núcleo da definição do conceito de pensamento espacial é encontrado no documento que constitui o grande pilar de referência mundial sobre essa temática, o relatório do Conselho Nacional de Pesquisa estadunidense (National Research Council - NRC), publicado em 2006, com o

1 No Brasil, a Educação Básica compreende os nove anos de escolaridade do ensino fundamental (numerados sequencialmente de 1 a 9 ) e três anos referentes ao ensino médio $\left(1^{\circ}\right.$ ao $3^{\circ}$ anos). título: Learning to Think Spatially: GIS as a Support System in the K-12 Curriculum². Em tradução livre: "Aprendendo a pensar espacialmente: Sistemas de Informações Geográficas como sistemas de apoio ao currículo da escola básica.

$\mathrm{Na}$ introdução do documento, encontramos uma definição que consolidou a compreensão dos três pilares cognitivos do spatial thinking: "Pensamento espacial - um tipo de pensamento - é baseado na amálgama de três elementos: conceitos espaciais, instrumentos de representação e processos de raciocínio" (NRC, 2006, ix). Os conceitos espaciais podem ser entendidos como os blocos construtivos básicos do pensamento espacial. Localização, direção, distância, orientação e movimento são exemplos de conceitos espaciais básicos que utilizamos para organizar e entender o mundo e como ele funciona.

Um segundo eixo ou dimensão do pensamento espacial diz respeito às formas de representação do espaço. No documento "Aprendendo a pensar espacialmente" há uma singela, mas significativa afirmação de que "Representações espaciais são poderosas ferramentas cognitivas que podem ampliar a aprendizagem e o pensamento" (NRC, 2006, p.281, tradução nossa). No mesmo documento, os autores afirmam que "Representações internas e externas produzem as formas como informações estruturadas são armazenadas, analisadas, compreendidas e comunicadas a outros" (NRC, 2006, p.25). As representações internas são aquelas em que a construção e a manipulação de imagens espaciais se dão na mente, o que demanda aquelas habilidades espaciais que são aferidas há tempos por testes psicométricos: visualização e orientação espaciais. Elas estão presentes nos mapas mentais e em imagens mentais que podemos construir para calcular, por exemplo, se a nova geladeira vai passar pela porta da cozinha. Já as representações externas, as que mais nos interessam neste trabalho, referem-se à capacidade de organizar, entender e comunicar informações com o uso de mapas, figuras e gráficos.

Assim, a conexão entre esses processos de raciocínio espacial e as formas de representação do espaço, notadamente aquelas vinculadas à Cartografia, são parte importante de nossa investigação sobre as relações entre a Cartografia Escolar e o desenvolvimento do pensamento espacial. Pensamos que uma citação constante do Guia Popular do Pensamento Espacial resumo bem o porquê:

Representações espaciais externas são importantes para os nossos processos de pensamento porque, uma vez que temos essa representação (mapa, diagrama, etc.) para entender a estrutura ou o processo espacial, nós podemos então voltar a nossa memória de trabalho disponível para focarmos no como e no porque da estrutura ou processo, ao invés de tentar lembrar

2 Nos Estados Unidos, a expressão K-12 refere-se à ampla fase de escolarização pré universitária que começa no jardim da infância, o kindergarten, e vai até o décimo segundo ano, que corresponde ao terceiro ano do ensino médio no Brasil. 
de muita coisa ao mesmo tempo. Daí porque muita gente desenha, seja em um guardanapo ou no quadro branco, enquanto estão pensando sobre e com o espaço. (Sinton et al, 2013, p.33, grifos originais e tradução nossa).

Os processos de raciocínio constituem o terceiro aspecto do pensamento espacial. Eles são importantes por diversos motivos, mas queremos enfatizar, em primeiro lugar, que esse terceiro elemento aponta para uma desembocadura prática do pensamento espacial. Na perspectiva fundamentada pelo NRC (2006) e incorporada pela comunidade científica, o pensamento espacial é orientado para a solução de problemas. Desenvolver o pensamento espacial é estar mais bem instrumentalizado para lidar com diferentes desafios, dos cotidianos aos científicos.

\section{A relevância do livro didático como um dos caminhos de avaliação do processo de ensino-aprendizagem}

Abordar a temática do livro didático e suas relações com o processo de ensino-aprendizagem é arriscar-se em um campo com muitas polêmicas, incertezas e preconceitos. A própria definição do que vem a ser um livro ou manual didático já é motivo para debate. Em última análise e tomando-se ao pé da letra a acepção do substantivo adjetivado, qualquer livro poderia ser considerado como didático, uma vez que pode ser utilizado para a finalidade educativa, de forma sistemática e planejada. É o que ocorre, por exemplo, com livros de literatura que são utilizados como meios para a compreensão das características de um determinado estilo literário ou para outros estudos.

Neste trabalho utilizaremos a definição de Richaudeau (1979, p. 5, apud Santos, 2003, p.107) segundo o qual "o livro didático será entendido como um material impresso, estruturado, destinado ou adequado a ser utilizado em um processo de aprendizagem ou formação".

A nossa opção por essa definição está centrada no fato de que ela incorpora o caráter teleológico da elaboração desse tipo de publicação. Toda a concepção de um livro didático tem como foco a sua finalidade de ser parte da mediação entre aprendiz e conhecimento, orquestrada pelo professor. Seleção e sequência de conteúdos, conceitos, linguagem textual, diagramação, linguagens visuais, atividades e muitos outros elementos tem sempre (ou deveriam ter) como eixo integrador a meta da aprendizagem.

Entendemos também que a relação entre livros didáticos e currículo reforça a pertinência de analisar essas obras didáticas como estratégia de pesquisa na área do ensino, o que se aplica aos nossos propósitos de tentar dimensionar o seu grau de contribuição para o desenvolvimento do pensamento espacial, nos moldes aqui apresentados.

\section{Livros didáticos, suas atividades pedagógicas e o desenvolvimento do pensamento espacial}

Considerando a demonstrada pertinência de avaliar os livros didáticos como uma das referências das práticas educativas e a grande variedade temática dos estudos voltados para o escrutínio dessas publicações em todas as disciplinas da escola básica, entendemos ser imperativo justificar, mesmo que brevemente, a relevância do caminho de análise que escolhemos, o qual envolve as atividades pedagógicas dessas obras.

Nossa perspectiva converge com a de Jo e Bednarz: "Questões constituem parte essencial dos livros didáticos" (2009, p.6, tradução nossa). Essa dupla de autoras faz numerosas citações de estudos empíricos de autores norte-americanos comprovando que as questões presentes em livros didáticos resultam em diversos aspectos positivos, sempre considerando que existe a influência do uso que cada professor faz dessas atividades: melhoram a compreensão do conteúdo pelos estudantes; ajudam os alunos a identificar as informações essenciais contidas no livro didático; auxiliam a construir estratégias para utilizar as informações fornecidas e estimulam as habilidades de solução de problemas pelos estudantes (Jo \& Bednarz, 2009, p.7).

Castellar e Moraes (2010) constituem outro exemplo de autoras que defendem o cuidado com a qualidade das atividades presentes nos livros didáticos:

Nesse contexto, o aluno deveria ser capacitado, a partir das atividades de aprendizagem, a não apenas repetir os conteúdos, mas também organizar, comparar, relacionar, analisar as informações. Essa prática tornaria o uso do livro mais eficaz, contribuindo para o desenvolvimento de um saber escolar que permitiria ao aluno estabelecer relações com o seu conhecimento não-formal adquirido em sua vivência social, cultural, religiosa e política. (p.140).

Estamos afinados com esses e outros autores que advogam o maior relevo que deve ser dado à qualidade das atividades pedagógicas presentes nos livros didáticos, no sentido de que elas devem ser cuidadosamente planejadas, de acordo com as finalidades da aprendizagem pretendida e em coerência com os fundamentos teórico-metodológicos e pedagógicos que fazem parte da proposta da obra. Entendemos que nossa iniciativa de realizar o escrutínio dessas atividades sob o prisma do desenvolvimento do pensamento espacial pode ser um passo no sentido dessa valorização. 


\section{Metodologia}

Entendemos que o caminho mais promissor e bem fundamentado para a nossa investigação está baseado na metodologia desenvolvida e aplicada por Jo e Bednarz (2009). Essa metodologia constitui o único esforço teórico conhecido no sentido de mensurar, com sólida fundamentação científica, o nível exigido de pensamento espacial presente nas questões e atividades pedagógicas dos manuais escolares.

Essencialmente, no nosso caso, trata-se de adaptar e aplicar uma taxonomia, desenvolvida para essa finalidade, como instrumento de avaliação dos exercícios e atividades presentes nas coleções de livros didáticos da disciplina de Geografia, destinados ao segmento do $6^{\circ}$ ao $9^{\circ}$ ano do ensino fundamental brasileiro, com o objetivo de aferir o percentual desses exercícios e atividades que efetivamente demandam o uso do pensamento espacial, assim como o nível cognitivo demandado para a sua solução.

Porém, a metodologia que será adotada, a partir de uma adaptação da Taxonomia de Jo e Bednarz, não está limitada ao binário demanda ou não demanda do pensamento espacial. Inclui também um aspecto muito importante, que é a complexidade das operações cognitivas envolvidas na solução da questão.

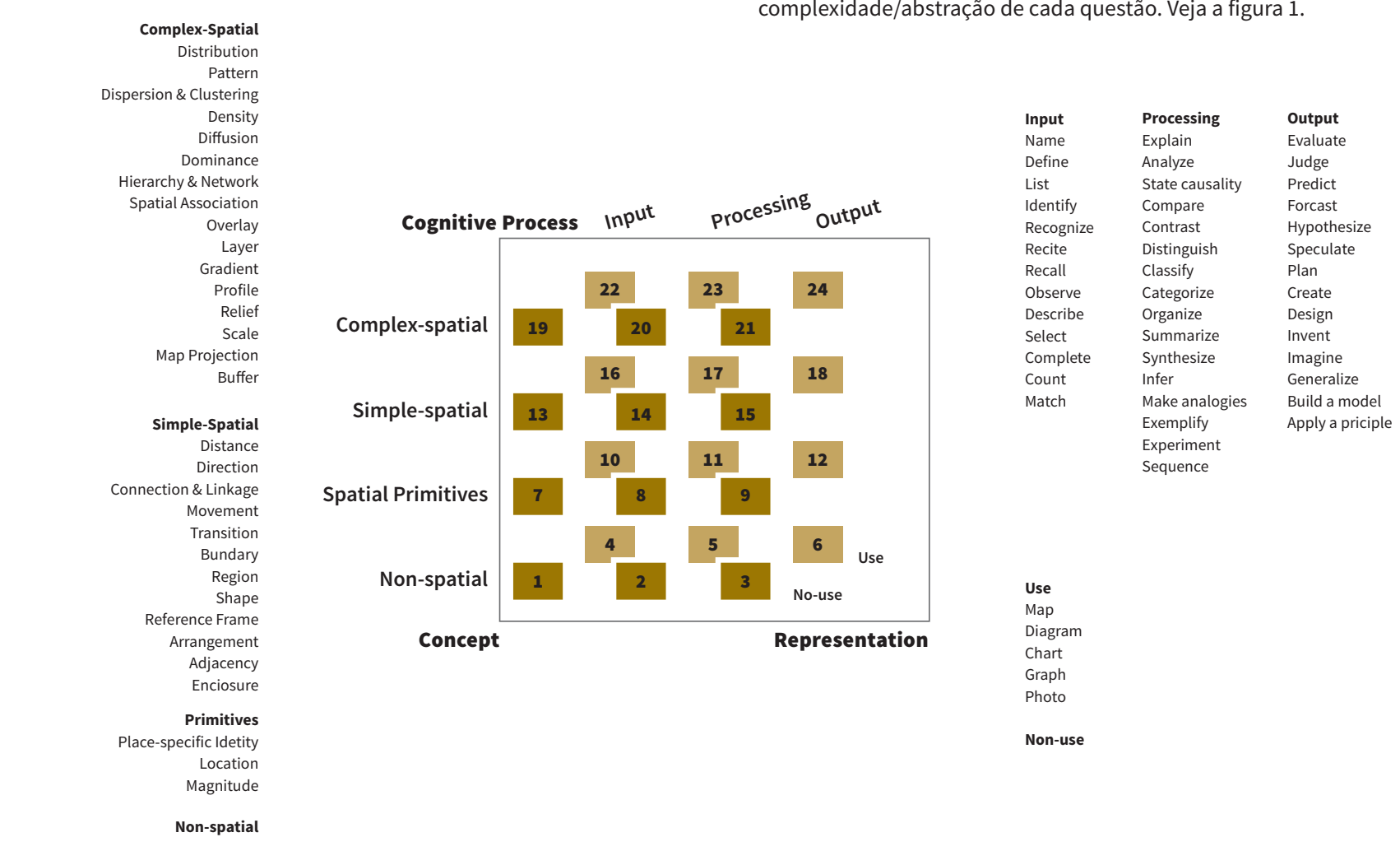

$\begin{array}{lll}\text { Input } & \text { Processing } & \text { Output } \\ \text { Name } & \text { Explain } & \text { Evaluate } \\ \text { Define } & \text { Analyze } & \text { Judge } \\ \text { List } & \text { State causality } & \text { Predict } \\ \text { Identify } & \text { Compare } & \text { Forcast } \\ \text { Recognize } & \text { Contrast } & \text { Hypothesize } \\ \text { Recite } & \text { Distinguish } & \text { Speculate } \\ \text { Recall } & \text { Classify } & \text { Plan } \\ \text { Observe } & \text { Categorize } & \text { Create } \\ \text { Describe } & \text { Organize } & \text { Design } \\ \text { Select } & \text { Summarize } & \text { Invent } \\ \text { Complete } & \text { Synthesize } & \text { Imagine } \\ \text { Count } & \text { Infer } & \text { Generalize } \\ \text { Match } & \text { Make analogies } & \text { Build a model } \\ & \text { Exemplify } & \text { Apply a priciple } \\ & \text { Experiment } & \end{array}$

Figura 1 - Fonte: Bednarz e Jo (2009, p.6)
Entendemos que, se é verdade que os exercícios e atividades presentes nos livros didáticos são uma poderosa ferramenta para a construção do pensamento espacial dos estudantes, o corolário lógico é que aferir a proporção desses exercícios e atividades que efetivamente necessitam/ estimulam o pensamento espacial é uma válida variável proxy para julgarmos em que medida os livros didáticos de Geografia estão contribuindo para que os estudantes desenvolvam essa forma de pensamento. Considerando também que os manuais escolares representam a principal ferramenta didática para grande parte dos professores brasileiros concluímos que esse caminho metodológico é promissor como uma das formas válidas para aquilatar a contribuição da dupla Cartografia Escolar/Educação Geográfica para o pensamento espacial.

\section{Taxonomia do pensamento espacial}

O primeiro aspecto fundamental da metodologia de análise desenvolvida por Bednarz e Jo (2009) foi a elaboração de uma taxonomia para classificar as questões de acordo com o nível de pensamento espacial envolvido em sua solução. A taxonomia de Bednarz e Jo classifica cada questão ou atividade pedagógica em 24 células, de acordo com os três componentes do pensamento espacial. Para cada um desses componentes há subcategorias, utilizadas principalmente para classificar o nível de complexidade/abstração de cada questão. Veja a figura 1. 
Apesar da ampla e sólida fundamentação teórica da taxonomia elaborada por Jo e Bednarz, fomos levados à escolha de não aplicá-la ipsis litteris em nosso processo de análise das coleções didáticas selecionadas para o nosso trabalho. Dessa forma, não vamos classificar cada questão em uma escala crescente de complexidade do pensamento espacial, que vai de 1 a 24, como propõe a dupla de pesquisadoras. A razão para essa decisão está ligada à polêmica envolvendo a decisão das autoras de hierarquizar os conceitos espaciais em primitivos, simples e complexos, com o que não concordam autores como Gersmehl (2014).

Entretanto, manteremos na nossa metodologia um aspecto central da taxonomia de Jo e Bednarz (2009), ou seja, a hierarquização das modalidades de pensamento espacial, de acordo com o nível de complexidade da operação cognitiva demandada por cada questão ou atividade presente nos livros didáticos.

Em virtude dos nossos propósitos estarem associados às relações entre a Cartografia Escolar/Educação Geográfica e o seu papel para o desenvolvimento do pensamento espacial do estudante do segundo segmento do ensino fundamental, decidimos acrescentar um registro ao fluxograma original construído por Scholz, Huynh, Brysch e Scholz (2014) para aplicação da classificação taxonômica de Jo e Bednarz (2009). Ao identificarmos que uma determinada questão envolvia o pensamento espacial, registramos também em qual dos cinco tipos de representação do espaço ela estava enquadrada. Veja a figura 2.

\section{Fluxograma simplificado para aplicação da Taxonomia de Jo e Bednarz}

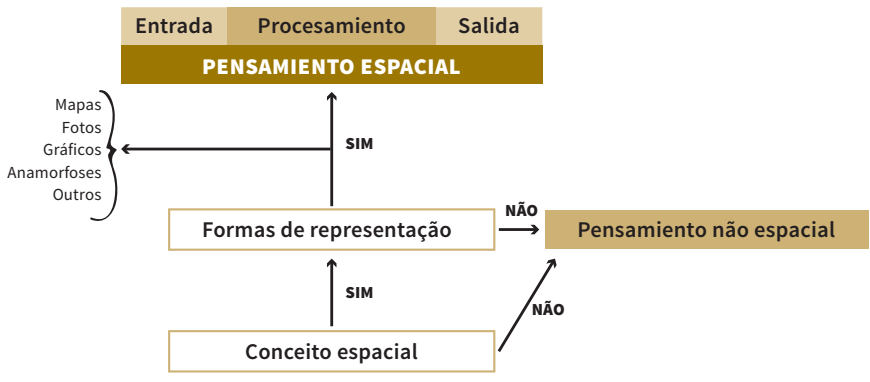

Figura 2 - Elaborado pelo autor a partir de Scholz et al. (2014, p.216)

\section{Análise das coleções}

Aplicamos a metodologia apresentada na seção precedente em três coleções brasileiras de Geografia para o segmento do $6^{\circ}$ ao $9^{\circ}$ ano do ensino fundamental, as quais estão nomeadas a seguir: Projeto Araribá; Expedições Geográficas; Projeto Teláris. O critério por nós utilizado para selecionar as três coleções listadas foi o da relevância, por serem elas as mais utilizadas pelos professores brasileiros.
Buscando aumentar as possibilidades de comparação com o cenário internacional, decidimos aplicar também a nossa metodologia de análise das questões a uma coleção de livros didáticos franceses destinados ao mesmo segmento escolar das coleções brasileiras avaliadas. Trata-se da coleção "Histoire-Géographie"3, sob a direção de Vincent Adoumié (à frente de um grupo de sete coautores).

\section{Uso ou não uso do pensamento espacial: um panorama geral}

O primeiro passo da nossa análise global das coleções remete ao foco da nossa questão central da pesquisa, ou seja, verificar o percentual de questões e atividades didáticas que efetivamente utilizam as imagens presentes nos manuais analisados para desenvolver o pensamento espacial dos estudantes. Em outras palavras, qual o percentual de questões/atividades que, obedecendo a sequencia do fluxograma da Figura 2, foram classificadas como demandando um conceito espacial e uma forma de representação do espaço. Os percentuais gerais podem ser visualizados baixo, no Gráfico 1 .

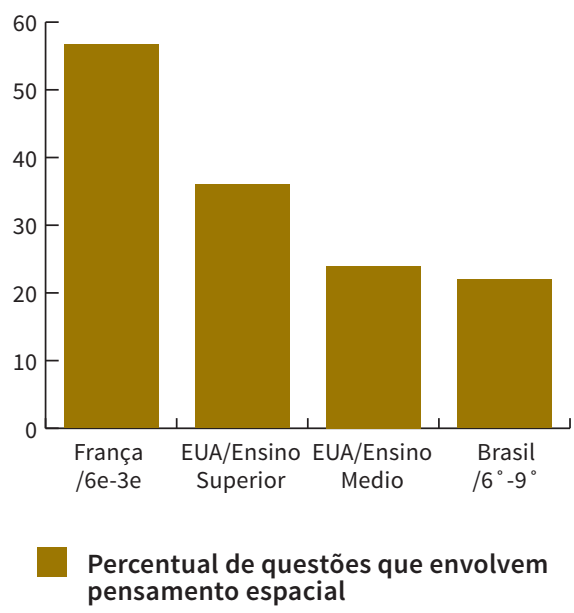

Gráfico 1 - Percentual de questões que envolvem pensamento espacial

O primeiro destaque do gráfico é o percentual bastante elevado da coleção francesa analisada. Por outro lado, as coleções brasileiras estão na lanterna nesse quesito fundamental para a nossa pesquisa. Mas é preciso fazer alguns enquadramentos referentes ao resultado dos levantamentos norte-americanos.

3 Na França a Geografia não existe como disciplina independente para o segmento que equivale ao $6^{\circ} / 9^{\circ}$ anos do Brasil. Os livros são divididos em uma metade dedicada à História e outra à Geografia e as aulas são ministradas por professores certificados em ambas as áreas para esse nível específico de ensino. 
Poderia-se argumentar que o percentual brasileiro não é tão ruim se considerarmos que os manuais didáticos dos EUA destinavam-se aos níveis médio e superior, enquanto que as coleções brasileiras foram editadas para o final do ensino fundamental. Entretanto, é importante deixar claro que os percentuais de questões que demandam pensamento espacial nos livros didáticos estadunidenses estão longe de ser um padrão considerado adequado para esse objetivo educacional e isso é apontado pelos próprios autores do levantamento (Jo \& Bednarz, 2009, p.10).

Outro resultado importante do nosso levantamento foi a relevante incoerência entre os dados obtidos e aquilo que deveria ser o padrão favorável ao desenvolvimento do pensamento espacial através das questões e atividades presentes nas coleções didáticas avaliadas. Trata-se do percentual de questões que operam com essa modalidade cognitiva em cada volume, de acordo com a faixa etária à qual se destina. Observe o gráfico 2 .

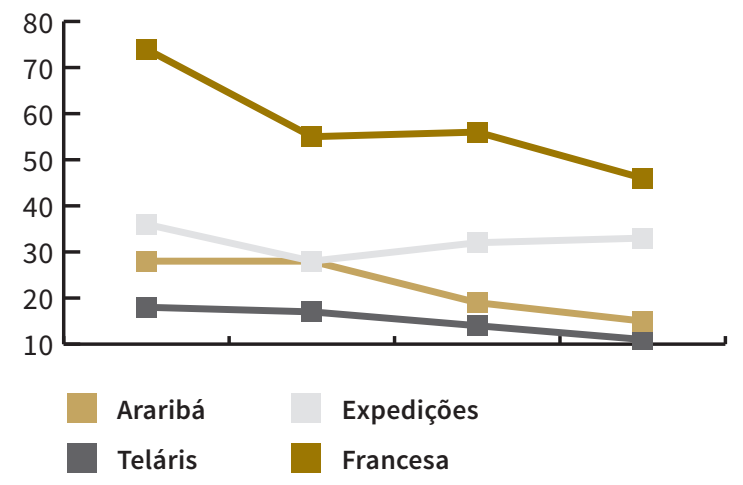

Gráfico 2 - Percentual de questões que envolvem pensamento espacial por ano de escolaridade em cada coleção

Considerando o amadurecimento cognitivo dos educandos ao longo desses expressivos quatro anos do segundo segmento do ensino fundamental, era esperado que o percentual de questões que envolvem o pensamento espacial fosse aumentando gradualmente ao longo do segmento de ensino. Esperávamos, pelo menos, que fosse possível identificar uma mudança do biênio correspondente ao $6 \% / 7^{\circ}$ anos para o do $8^{\circ} / 9^{\circ}$. Não é essa a realidade constatada a partir dos dados do gráfico 2 . Ao contrário, verifica-se expressivo declínio daquele percentual entre o sexto e o nono anos.

Essa tendência apontada no gráfico vai totalmente de encontro ao amadurecimento intelectual do estudante desse segmento, o que significa que as questões estão aquém do que os estudantes do final do ensino fundamental poderiam realizar em termos de pensamento espacial. Para usar um conceito caro à teoria cognitiva de Vygotsky, do ponto de vista do spatial thinking, a maior parte das questões presentes nas coleções didáticas analisadas está trabalhando abaixo da zona de desenvolvimento proximal dos educandos

\section{Nível dos processos de raciocínio envolvido nas questões que demandam o pensamento espacial com o uso de mapas}

$\mathrm{Na}$ avaliação mais geral das coleções quanto à presença de questões que exigem o pensamento espacial para a sua resolução, tomamos o cuidado de avaliar também o nível cognitivo demandado nessas questões, segunda a classificação presente na Taxonomia de Jo e Bednarz (Entrada, Processamento e Saída). Nesta etapa de nossa abordagem, focada na relação entre Cartografia e pensamento espacial nos livros didáticos, queremos recorrer a essa mesma camada de análise para refinar as nossas observações. Com esse objetivo, apresentaremos dados das quatro coleções analisadas referentes especificamente ao nível cognitivo demandado das questões com pensamento espacial baseadas em mapas. Veja o gráfico 3.

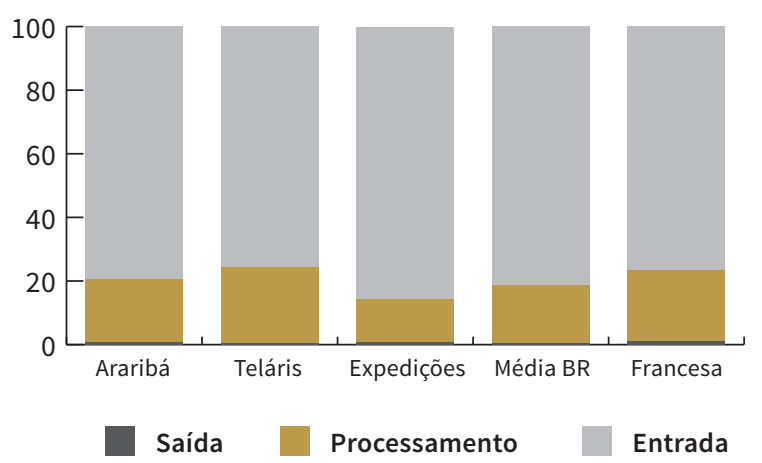

Gráfico 3 - Hierarquização das questões que envolvem pensamento espacial com base em representações cartográficas - Média das coleções avaliadas $(\%)$

Ao analisarmos o gráfico 3 avaliamos que o quadro geral é bastante negativo frente aos objetivos de se desenvolver o pensamento espacial dos alunos através do par Cartografia Escolar/Educação Geográfica. Sabemos que a faixa etária a qual é destinada esse tipo de coleção (aproximadamente entre os 11 e os 14 anos) encontra-se na transição do estágio das operações concretas para o estágio das operações formais, de acordo com a conhecida elaboração de Piaget. Em outras palavras, os alunos estão começando a desenvolver o seu raciocínio de caráter abstrato e isso se aplica também, naturalmente, ao campo do pensamento espacial. 
Dessa forma, seria incoerente esperar que grande proporção das questões envolvessem operações cognitivas complexas. Mesmo assim, consideramos que o percentual irrisório (igual ou inferior a um por cento) de questões com esse perfil sinaliza a necessidade de projetar atividades que apontem na direção dessas habilidades cognitivas mais sofisticadas.

Contudo, entendemos que o nó do problema que precisa ser enfrentado doravante pelos autores de livros didáticos de Geografia, está ligado à proporção elevadíssima de questões espaciais com o uso do mapa que demandam habilidades operatórias de "Entrada", tais como nomear, descrever, identificar, reconhecer, observar, entre outras. 0 fato de que entre 75 a 85 por cento dessas questões estarem enquadradas nesse nível cognitivo é, a nosso juízo, um atestado inequívoco da subutilização da Cartografia nos anos finais do ensino fundamental.

Outro problema relacionado a esse elevado percentual médio de questões espaciais de "entrada" é que os percentuais se mantém de forma praticamente inalterada ao longo de todo o segmento de ensino, tanto para o conjunto das representações espaciais quanto para as questões espaciais baseadas em representações cartográficas. Observe os dados do gráfico 4 e 5.

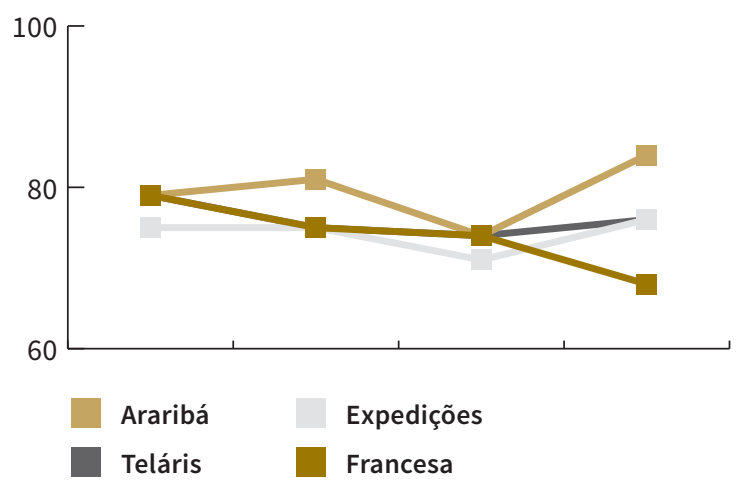

Gráfico 4 - Percentual de questões que envolvem pensamento espacial classificadas como de "Entrada" por volume de cada coleção avaliada (\%)

A análise combinada dos dois gráficos nos permite constatar que, para o conjunto geral das questões que envolvem o pensamento espacial, é visível a estabilidade das curvas das quatro coleções, com um pequeno desvio da média, representado pela coleção Araribá, na qual há um decréscimo de apenas 10 pontos percentuais ao longo dos quatro anos de escolaridade abrangidos pelas coleções.

O panorama não é muito diferente no que toca às questões espaciais baseadas nos mapas em geral (gráfico 5). Na coleção Expedições os percentuais mantêm-se praticamente inalterados ao longo dos quatro anos, em níveis sempre superiores a $80 \%$. Na coleção Teláris e na coleção
Adoumié, verifica-se, para ambas, um comportamento idêntico. Há redução das questões de "entrada" no oitavo ano, ainda que não muito significativa (cerca de $10 \%$ a $12 \%$ ), mas no nono ano o percentual retorna para o patamar verificado no sexto ano, o que gera a impressão de que a redução verificada no oitavo ano não foi intencional. Já a coleção Araribá mantém os percentuais por três anos, para reduzir em $15 \%$ as questões de "entrada" apenas no nono ano.

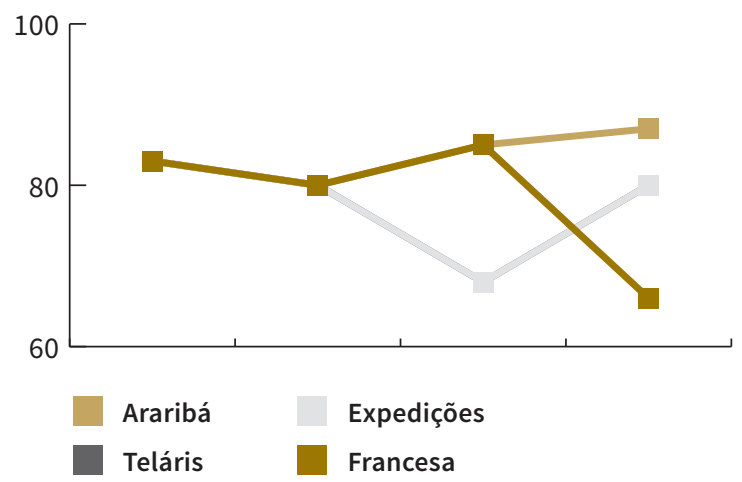

Gráfico 5 - Percentual de questões que envolvem pensamento espacial com base em representações cartográficas classificadas como de "Entrada" por volume de cada coleção avaliada (\%)

Todo esse quadro sugere que não há preocupação, pautada em alguma fundamentação teórico-metodológica, de dosar o nível de complexidade das questões que envolvem a Cartografia ao longo dos anos finais do ensino fundamental. Sem dúvida essa despreocupação compromete seriamente o avanço da proficiência cartográfica dos estudantes e o desenvolvimento do seu pensamento espacial. Ainda mais se considerarmos que é nesse segmento (especialmente nos últimos dois anos) que o aluno está sendo preparado para lidar com os conteúdos do ensino médio, segmento escolar no qual a demanda por níveis mais elevados de abstração e generalização são mais acentuados.

\section{Conclusões}

Imaginávamos, já a princípio, que não encontraríamos um cenário favorável ao desenvolvimento do pensamento espacial nesses manuais, mas é preciso admitir que a realidade demonstrou ser ainda pior do que projetávamos. A análise das três coleções didáticas mais vendidas no Brasil (para o segmento de $6^{\circ}$ a $9^{\circ}$ anos) aponta para um cenário muito negativo, no que se refere à possibilidade desses recursos pedagógicos darem apoio à construção do spatial thinking dos discentes.

Portanto, nessa dupla tentativa de interlocução de nossa parte com os autores de livros didáticos e com os professores de Geografia, queremos reforçar as nossas recomendações a ambos. Para os editores e autores 
de livros didáticos da Geografia queremos apelar para que eles incluam os três elementos do pensamento espacial como fatores importantes na elaboração dessas obras, em especial no que tange aos exercícios e atividades incluídas nesses volumes.

Para os professores, queremos conclamá-los a considerarem o potencial de desenvolvimento do pensamento espacial na sua próxima seleção de livros didáticos para adoção. De preferência usando (de forma simplificada e amostral) a lógica de avaliação que desenvolvemos neste trabaIho. Ao mesmo tempo, queremos adverti-los que as limitações atuais das coleções que temos à disposição, no que diz respeito ao desenvolvimento do spatial thinking, não devem desanimá-los.

\section{Referências}

Castellar, S M. V. \& Moraes, J. V.(2010). Ensino de Geografia. São Paulo: Cengage Learning.

Gersmehl, P. (2014). Teaching Geography. $3^{\text {rd }}$ ed. New York: Guilford Press.

Jo, I. \& Bednarz, S.(2009). Evaluating geography textbook questions from a spatial perspective: Using concepts of space, tools of representation, and cognitive processes to evaluate spatiality. Journal of Geography, 108.4-13. Recuperado em 05 de setembro de 2013 de http://dx.doi.org/10.1080/00221340902758401

National Research Council. (2006). Learning to think spatially: GIS as a support system in the K-12 curriculum. Washington: National Research Council Press. ISBN: 0-309-53191-8, 332 pp Recuperado em 3 de julho de 2013 de http:// www.nap.edu/catalog/11019.html

Santos, C. (2003). A Cartografia nos livros didáticos de Geografia: contrapontos de uma pesquisa. Revista de Ciências Humanas, 9, (2), pp. 107-114.

Scholz, M. A.; Huynh, N. T.; Brysch, C. P. \& Scholz, R. W. (2014). An Evaluation of University World Geography Textbook Questions for Components of Spatial Thinking, Journal of Geography, 113(5), pp. 208-219. ISSN 0022-1341

Sinton, D. S.; Kolvoord, R.; Gersmehl, P.; Ries, P.; Bernarz, S., \& Uttal, D. H. (2013). The People's Guide to Spatial Thinking. Washington: National Council for Geographic Education. 